\title{
Neurophobia Inception: A Study of Trainees' Perceptions of Neurology Education
}

\author{
Tadeu A. Fantaneanu, Katherine Moreau, Kaylee Eady, Chantalle Clarkin, \\ Christine DeMeulemeester, Heather Maclean, Asif Doja
}

\begin{abstract}
Objectives: We wanted to examine the extent to which "neurophobia" exists among medical students and determine if students' perceptions of neurology differ by year of study while exploring the factors that contribute to the development of "neurophobia". Methods: We used a two-phase, sequential, mixed-methods explanatory design in this single centre study. Phase 1 involved the collection and analysis of a questionnaire administered to students in the first three years of medical school. Phase 2 involved focus groups of a subgroup of students who demonstrated evidence of neurophobia in Phase 1. Results: In total, 187 (39 \%) undergraduate medical trainees responded to the questionnaire (response rates of $37 \%, 44 \%$ and $19 \%$ for first-, second- and third-year students, respectively). $24 \%$ of respondents indicated that they were afraid of clinical neurology and $32 \%$ were afraid of the academic neurosciences. Additionally, $46 \%$ of respondents thought that clinical neurology is one of the most difficult disciplines in medicine. Phase 2 findings revealed that many students reported negative preconceptions about neurology and commented on neurology's difficulty. Some experienced changes in these conceptions following their neurology block. Past clinical, educational, and personal experiences in neurology impacted their comfort level. Conclusions: This study shows that the level of comfort towards clinical neurology increases following students' participation in second-year neurology blocks, but that third-year students continue to show signs of neurophobia with lower comfort levels. It provides insight into why neurophobia exists amongst medical students and sheds light on pre-existing and emerging factors contributing to this sense of neurophobia.
\end{abstract}

RÉSUMÉ: Émergence de la neurophobie : une étude des perceptions des stagiaires sur la formation en neurologie. Objectifs : Nous voulions examiner dans quelle mesure la neurophobie existe parmi les étudiants en médecine et déterminer si les perceptions des étudiants diffèrent selon leur niveau de formation, tout en explorant les facteurs qui y contribuent. Méthode : Nous avons utilisé un devis d'étude de type mixte, séquentiel, en deux phases et l'étude a été réalisée dans un seul centre. Au cours de la phase 1, nous avons recueilli et analysé un questionnaire rempli par les étudiants des trois premières années de la faculté de médecine. La phase 2 impliquait des groupes de discussion formés d'étudiants ayant manifesté de la neurophobie au cours de la phase 1. Résultats : En tout, 187 (39\%) des étudiants en médecine ont répondu au questionnaire (taux de réponse de 37\%, 44\% et 19\% pour ceux de première, deuxième et troisième année respectivement). Vingt-quatre pour cent des répondants ont indiqué qu'ils entretenaient des craintes envers la neurologie clinique et $32 \%$ envers les neurosciences académiques. De plus, $46 \%$ des répondants croyaient que la neurologie clinique était la discipline la plus difficile de la médecine. Lors de la phase 2, nous avons constaté que plusieurs étudiants avaient des idées préconçues au sujet de la neurologie et ils ont fait des commentaires sur la difficulté de la neurologie. Certains ont modifié leur opinion après leur stage en neurologie. Des expériences cliniques, pédagogiques et personnelles antérieures en neurologie influençaient leur niveau de confort. Conclusions : Cette étude montre que le niveau de confort envers la neurologie clinique augmente suite à la participation des étudiants aux stages en neurologie au cours de leur deuxième année de formation, mais que des signes de neurophobie associés à un niveau de confort plus faible persistent chez des étudiants de troisième année. Cette étude permet de comprendre pourquoi la neurophobie existe chez les étudiants en médecine et fournit des renseignements sur les facteurs préexistants et émergeants qui y contribuent.

Can J Neurol Sci. 2014; 41: 421-429

The burden of neurological disease is intensifying ${ }^{1}$. Recent reports suggest that, on a yearly basis, 67 of every 1000 Americans will carry a diagnosis of Alzheimer's disease and that 10 of every 1000 Americans will have a diagnosis of Parkinson's disease $^{2}$. Younger American populations are also affected. For example, prevalence rates of migraine headaches, epilepsy and multiple sclerosis are $121,7.1$ and 0.9 per 1000 patients, respectively ${ }^{2}$. A report from the Canadian Institute for Health Information also found that neurological conditions represent
From the Department of Medicine, Division of Neurology (TAF, CD, HM, AD) Department of Pediatrics (KM, AD), Faculty of Medicine, University of Ottawa; Children's Hospital of Eastern Ontario Research Institute (KM, KE, CC), Ottawa, Ontario, Canada.

Received December 10, 2013. Final Revisions Submitted March 3, 2014. Correspondence to: Asif Doja, Division of Neurology, Children's Hospital of Eastern Ontario, 401 Smyth Road, Ottawa, Ontario, K1H 8L1, Canada. Email: adoja@cheo.on.ca. 
$9 \%$ of acute care hospitalizations and that $19 \%$ of patient days in acute care facilities were for patients with neurological illnesses or injuries. Moreover, $20 \%$ of patients receiving inpatient rehabilitation had one of the six common neurological injuries (i.e., head injury, multiple sclerosis, Parkinson's disease, spinal injury, and stroke $)^{3}$.

Not only are neurological illnesses often insidious in their presentation, they are seldom curable and often amount to a high level of disability ${ }^{2}$. Given the prevalence and impact of neurological conditions, more demand is being placed on healthcare systems to deliver high quality neurological care and therefore physicians cannot afford to be ill prepared in their approaches to this area of medicine.

Unfortunately, studies have shown that practitioners and trainees share a common dislike for the neurological sciences and some develop neurophobia ${ }^{4}$. First described by Jozefowicz, neurophobia is a "fear of the neural sciences and clinical neurology that is due to the students' inability to apply their knowledge of basic sciences to clinical situations" ". Although the term neurophobia was coined by Jozefowicz, the concept was reported as early as 1959 by Poser who surveyed third- and fourth-year students' attitudes towards neurology. Respondents perceived the large number of incurable diseases in neurology as being unattractive and identified preceptors and course presentations as possible barriers to selecting neurology as a career. $^{5}$

Neurophobia has often been linked to students' and physicians' perceived difficulty with or limited knowledge of neurology. Schon et $a l^{6}$ conducted a survey aimed at medical students and general practitioners in the United States (U.S.) and found that neurology was ranked as the most difficult of the subspecialties. The authors identified poor quality neurology teaching and difficulty with clinical neurological examinations as common reasons for this perception. Similar findings emerged from a survey conducted by Flanagan et al in Ireland ${ }^{7}$. Aimed at students and junior physicians from various medical institutions across the country, they found that neurology was perceived as the most difficult subject among all other medical subspecialties and that poor quality of teaching in neurology as well as limited exposure to neurological patients were possible explanations for these findings ${ }^{7}$. In addition, similar conclusions were drawn by researchers in both the Caribbean and the U.S. ${ }^{8,9}$. Making this a truly global phenomenon were more recent studies from Sri Lanka and India confirming the presence of neurophobia amongst their undergraduate and postgraduate trainees and outlining how this might go so far as to affect their career choices, often avoiding neurology ${ }^{10,11}$.

While the use of quantitative methods in these studies provided some insight into the perceived difficulties and the potential existence of neurophobia, they did not allow for a detailed, multifaceted exploration of the issues and problems from the perspectives of the medical trainees themselves. Moreover, these studies did not look at when neurophobia develops. As such, the primary goal of this two-phase mixedmethods study was to examine the extent to which neurophobia exists among selected undergraduate medical students and determine if students' perceptions of neurology differ significantly by year of study. As a secondary goal, the study aimed to explore why neurophobia develops, including the factors that contribute to its genesis.

\section{MeTHODS}

Ethical approval was obtained from the Children's Hospital of Eastern Ontario Research Ethics Board.

\section{Research Design}

This study employed a two-phase, sequential, mixed methods explanatory design. Phase 1 involved the collection and analysis of quantitative data via a questionnaire. The purpose of this phase was to examine the extent to which neurophobia exists among selected undergraduate medical students and determine if students' perceptions of neurology differ significantly by year of study. Building on the results from Phase 1, Phase 2 involved the collection and analysis of qualitative data through focus groups $^{12}$. The purpose of Phase 2 was to explore why neurophobia develops, including the factors that contribute to its genesis.

\section{Sample}

Phase 1. A convenience sampling approach was used. All medical trainees in first, second, and third year at the University of Ottawa were invited to participate. At this institution, medical trainees have approximately six weeks of didactic teaching and case-based learning in neurology (Neurology block) in their second year. For the purposes of this study, second-year trainees were surveyed after completing their Neurology block.

Phase 2. In this phase, the goal was to obtain informationrich data and as such, a purposeful sampling approach was used $^{13}$. To ensure that Phase 2 participants had information and insights on neurophobia, the study sample was drawn from those who had shown potential evidence of neurophobia in Phase 1 from their responses to selected questions (based on answering 'agree' or 'strongly agree' to questions 1-1, 1-2, and 'disagree' or 'strongly disagree' to 2-4, 2-5 and 3-5, as outlined in Tables 1 through 3 below).

\section{Instrument Development}

Phase 1. After an extensive review of the literature, an online questionnaire was developed (Supplemental e-1). The questionnaire focused on: (a) students' general perceptions of neurology and neuroscience as well as their neurological education; (b) students' perceived level of knowledge in neurology and neuroscience; (c) students' perceived difficulty with neurology and neuroscience; (d) students' exposure to neurological patients; and (e) students' perceived level of fear of neurology and neuroscience. It included a four-point scale that asked students to indicate the degree to which they agree or disagree with items ( 1 = Strongly Disagree, $4=$ Strongly Agree.) There was also a Don't Know category. The questionnaire was reviewed by two content experts to ensure its validity. It was also piloted with ten medical trainees who were ineligible for the study.

Phase 2. The findings from Phase 1 informed the development of the focus group question guide (Supplemental e2). The guide consisted of an introductory script and various open-ended questions that explored why students develop neurophobia and the factors that contribute to its genesis. Participants were encouraged to provide examples of how their education and clinical experiences have contributed to their 
neurophobia or perceptions of neurology. The research team developed the guide and an independent qualitative research consultant reviewed the guide. An external expert in neurophobia also reviewed the guide for content validity and ensured that the questions were appropriate, complete, and relevant to the topic $\operatorname{area}^{14}$.

\section{Procedure}

Phase 1. An electronic information letter and questionnaire link was circulated to all first-, second- and third-year medical trainees. Using a modified version of Dillman's Tailored Design Method, two reminder emails were sent to maximize the response rate $^{15}$. All responses were kept confidential. To recruit potential participants for Phase 2, respondents were asked to provide their email address if they were interested in participating in a follow-up focus group session.

Phase 2. Information letters were distributed to eligible participants. A trained qualitative moderator facilitated each focus group session, while a note taker observed and recorded the key points and non-verbal gestures of the participants. All sessions lasted approximately one hour. Each focus group session was audio-recorded and transcribed verbatim. All participants signed an informed consent form prior to the focus group.

\section{Analysis}

Phase 1. Analysis for Phase 1 data was completed in SPSS version 20. Descriptive statistics (frequencies and percentages) were used to examine the extent to which neurophobia exists among the trainees. Pearson chi-square tests were used to examine for differences in perceptions of students in different years of study. Two-sided p-values less than .05 were considered statistically significant, and corresponding 95\% confidence intervals were calculated using the Wilson score method.

Phase 2. A conventional qualitative content analysis was used $^{16}$. This approach ensured that the coding scheme was developed directly from the data. Two trained qualitative consultants independently read the focus group transcripts multiple times to obtain a sense of the whole ${ }^{17}$. They then read through the transcripts again to derive the initial coding scheme. Next, they sorted these codes into overarching categories based on how the codes related to one another. The consultants then met to compare and discuss their categorical systems and developed definitions for each category. They then reanalyzed

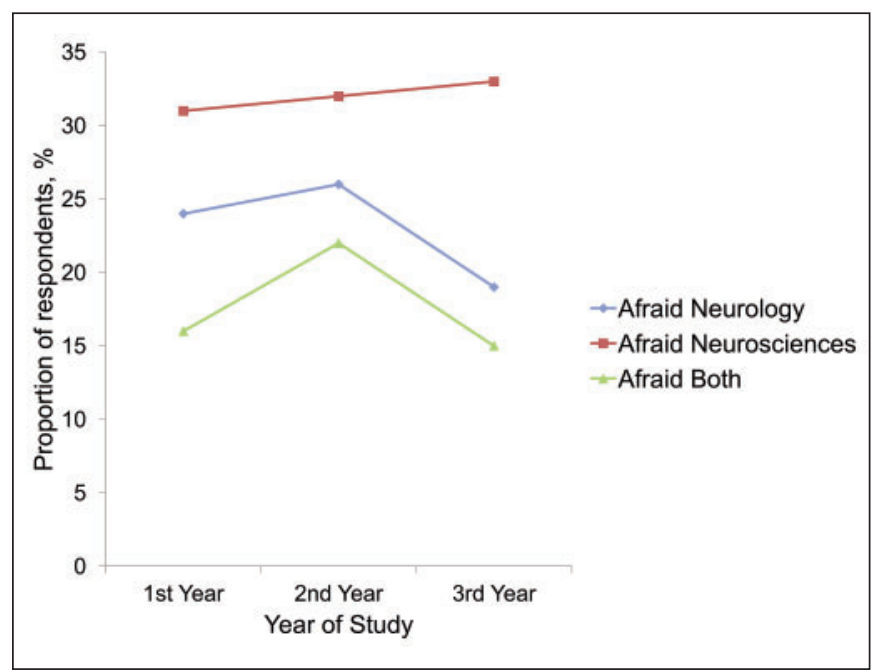

Figure 1: The existence of neurophobia among undergraduate medical students.

the transcripts using their agreed list of categories and codes and identified exemplars of each for reporting purposes.

\section{RESULTS}

\section{Characteristics of participants}

In total, 187 (39\%) undergraduate medical trainees responded to the questionnaire; $139(74 \%)$ respondents completed the survey in its entirety. Of the respondents, 69 (37\%) identified themselves as being in first year of undergraduate medical school (pre-Neurology block), 83 (44\%) in second year (postNeurology block), and 35 (19\%) in third year clerkship. In the subsequent phase of the study, seven first-, six second-, and six third-year medical students participated in three separate focus groups.

\section{The existence of neurophobia among selected undergraduate medical students.}

On the questionnaire, a considerable portion of respondents indicated that they were in fact afraid of clinical neurology or the academic neurosciences (Table 1, Figure 1), suggesting that neurophobia does exist among undergraduate medical trainees.

Table 1: Questionnaire indicators of neurophobia by year of study

\begin{tabular}{|c|c|c|c|c|c|c|c|c|c|c|c|c|c|}
\hline \multirow{2}{*}{\multicolumn{2}{|c|}{ Item }} & \multicolumn{3}{|c|}{ First year } & \multicolumn{3}{|c|}{ Second year } & \multicolumn{3}{|c|}{ Third year } & \multicolumn{3}{|c|}{ Overall } \\
\hline & & $\mathrm{N}$ & $\mathrm{n}$ & $\begin{array}{c}\text { Proportion, \% } \\
(95 \% \mathrm{CI})\end{array}$ & $\mathrm{N}$ & $\mathrm{n}$ & $\begin{array}{l}\text { Proportion, \% } \\
(95 \% \mathrm{CI})\end{array}$ & $\mathrm{N}$ & $\mathrm{n}$ & $\begin{array}{c}\text { Proportion, \% } \\
(95 \% \mathrm{CI})\end{array}$ & $\mathrm{N}$ & $\mathrm{n}$ & $\begin{array}{c}\text { Proportion, \% } \\
(95 \% \mathrm{CI})\end{array}$ \\
\hline 1. & $\begin{array}{l}\text { Afraid of clinical } \\
\text { neurology }\end{array}$ & 51 & 12 & $24(0.14,0.37)$ & 69 & 18 & $26(0.17,0.38)$ & 27 & 5 & $19(0.08,0.37)$ & 147 & 35 & $24 \%(0.18,0.31)$ \\
\hline 2. & $\begin{array}{l}\text { Afraid of academic } \\
\text { neurosciences }\end{array}$ & 51 & 16 & $31(0.20,0.45)$ & 69 & 22 & $32(0.22,0.44)$ & 27 & 9 & $33(0.19,0.52)$ & 147 & 47 & $32 \%(0.25,0.40)$ \\
\hline 3. & $\begin{array}{l}\text { Afraid of clinical } \\
\text { neurology and academic } \\
\text { neurosciences }\end{array}$ & 51 & 8 & $16(0.08,0.28)$ & 69 & 15 & $22(0.14,0.33)$ & 27 & 4 & $15(0.06,0.32)$ & 147 & 27 & $18 \%(0.13,0.25)$ \\
\hline
\end{tabular}


Table 2: Students' perceptions of neurology by year of study

\begin{tabular}{|c|c|c|c|c|c|c|c|c|c|c|}
\hline \multirow{2}{*}{\multicolumn{2}{|c|}{ Item }} & \multicolumn{3}{|c|}{ First year } & \multicolumn{3}{|c|}{ Second year } & \multicolumn{3}{|c|}{ Third year } \\
\hline & & $\mathrm{N}^{+}$ & $\mathrm{n}$ & $\begin{array}{l}\text { Proportion, \% } \\
(95 \% \mathrm{CI})\end{array}$ & $\mathrm{N}^{+}$ & $\mathrm{n}$ & $\begin{array}{l}\text { Proportion, \% } \\
(95 \% \mathrm{CI})\end{array}$ & $\mathrm{N}^{+}$ & $\mathrm{n}$ & $\begin{array}{l}\text { Proportion, \% } \\
(95 \% \mathrm{CI})\end{array}$ \\
\hline 1. & $\begin{array}{l}\text { I think clinical neurology is important to } \\
\text { the study of medicine in general }\end{array}$ & 52 & 51 & $98(0.90,1.00)$ & 69 & 69 & $100(0.95,1.00)$ & 27 & 27 & $100(0.88,1.00)$ \\
\hline 2. & $\begin{array}{l}\text { I think academic neuroscience is } \\
\text { important to the study of medicine in } \\
\text { general }\end{array}$ & 52 & 48 & $92(0.82,0.97)$ & 69 & 60 & $87(0.77,0.93)$ & 27 & 24 & $89(0.72,0.96)$ \\
\hline 3. & $\begin{array}{l}\text { I think clinical neurology is important for } \\
\text { general practitioners }\end{array}$ & 52 & 49 & $94(0.84,0.98)$ & 69 & 69 & $100(0.95,1.00)$ & 27 & 26 & $96(0.82,0.99)$ \\
\hline 4. & $\begin{array}{l}\text { I am comfortable with the subject of } \\
\text { clinical neurology*** }\end{array}$ & 52 & 7 & $14(0.07,0.25)$ & 69 & 50 & $73(0.61,0.82)$ & 27 & 14 & $52(0.34,0.69)$ \\
\hline 5. & $\begin{array}{l}\text { I am comfortable with the subject of } \\
\text { academic neuroscience } * * *\end{array}$ & 51 & 13 & $26(0.16,0.39)$ & 69 & 40 & $58(0.46,0.69)$ & 27 & 11 & $41(0.25,0.59)$ \\
\hline 6. & I think neuroanatomy is difficult*** & 52 & 24 & $46(0.33,0.59)$ & 68 & 49 & $72(0.60,0.81)$ & 27 & 19 & $70(0.52,0.84)$ \\
\hline 7. & I think clinical neurology is difficult*** & 51 & 17 & $33(0.22,0.47)$ & 69 & 45 & $65(0.53,0.75)$ & 26 & 16 & $62(0.43,0.78)$ \\
\hline 8. & $\begin{array}{l}\text { I think the clinical neurological } \\
\text { examination is difficult*** }\end{array}$ & 52 & 15 & $29(0.18,0.42)$ & 69 & 36 & $52(0.41,0.64)$ & 27 & 12 & $44(0.28,0.63)$ \\
\hline 9. & $\begin{array}{l}\text { I think clinical neurology is one of the } \\
\text { most difficult disciplines in medicine*** }\end{array}$ & 52 & 15 & $29(0.18,0.42)$ & 68 & 40 & $59(0.47,0.70)$ & 27 & 13 & $48(0.31,0.66)$ \\
\hline
\end{tabular}

+ Please note, $\mathrm{N}$ may vary from question to question. $* * * \mathrm{p}<.001$

\section{Undergraduate medical students' perceptions of neurology by year of study.}

Overall, the majority of respondents to the questionnaire in all years of study agreed that the subjects of clinical neurology and academic neuroscience are important to the study of medicine and that clinical neurology is also important for general practitioners (Table 2). Perceptions regarding their comfort level with these subjects and their related level of difficulty differed significantly by year of study (chi-square, all $\mathrm{p}<.001$ ), though neurophobia was present across all three years. Very few trainees in their first year of study indicated that they were comfortable with the subjects of clinical neurology and academic neuroscience, while the majority of second-year students (after their Neurology block) indicated that they were comfortable with these subjects. Interestingly, only half of the students in their third year of medical school indicated that they were comfortable with the subject of clinical neurology and less than half indicated that they were comfortable with the subject of academic neuroscience. In addition, $60 \%$ of first-year students reported not knowing whether clinical neurology is difficult in contrast to $65 \%$ of second-year students (post neuro block) whom "agree" or "strongly agree" that it is.

\section{Undergraduate medical students' perceptions of their} training in neurology by year of study.

While the majority of students in their third year of medical school indicated that they had adequate knowledge of academic neuroscience for their future practice, only one third indicated that they had adequate knowledge of clinical neurology (Table 3, Figure 2). The majority of students in all three years of study indicated that they have had limited exposure to neurological patients, that they would like more exposure to neurological

Table 3: Students' perceptions of their training in neurology by year of study

\begin{tabular}{|c|c|c|c|c|c|c|c|c|c|c|}
\hline & & \multicolumn{3}{|c|}{ First year } & \multicolumn{3}{|c|}{ Second year } & \multicolumn{3}{|c|}{ Third year } \\
\hline \multicolumn{2}{|c|}{ Item } & $\mathrm{N}^{+}$ & $\mathrm{n}$ & $\begin{array}{l}\text { Proportion, \% } \\
(95 \% \mathrm{CI})\end{array}$ & $\mathrm{N}^{+}$ & $\mathrm{n}$ & $\begin{array}{l}\text { Proportion, \% } \\
(95 \% \mathrm{CI})\end{array}$ & $\mathrm{N}^{+}$ & $\mathrm{n}$ & $\begin{array}{l}\text { Proportion, } \% \\
(95 \% \mathrm{CI})\end{array}$ \\
\hline 1. & $\begin{array}{l}\text { I am happy with the amount of education I have } \\
\text { received in clinical neurology*** }\end{array}$ & 52 & 4 & $8(0.03,0.18)$ & 70 & 64 & $91(0.83,0.96)$ & 27 & 15 & $56(0.37,0.72)$ \\
\hline 2. & $\begin{array}{l}\text { I am happy with the amount of education I have } \\
\text { received in academic neuroscience*** }\end{array}$ & 52 & 9 & $17(0.09,0.30)$ & 68 & 50 & $74(0.62,0.83)$ & 27 & 16 & $59(0.41,0.76)$ \\
\hline 3. & $\begin{array}{l}\text { I am happy with the quality of education I have } \\
\text { received in clinical neurology*** }\end{array}$ & 52 & 2 & $4(0.01,0.13)$ & 69 & 57 & $83(0.72,0.90)$ & 27 & 21 & $78(0.59,0.89)$ \\
\hline 4. & $\begin{array}{l}\text { I am happy with the quality of education I have } \\
\text { received in academic neuroscience*** }\end{array}$ & 52 & 10 & $19(0.11,0.32)$ & 69 & 47 & $68(0.56,0.78)$ & 26 & 18 & $69(0.50,0.84)$ \\
\hline 5. & $\begin{array}{l}\text { I have adequate knowledge of clinical neurology } \\
\text { for my future practice*** }\end{array}$ & 52 & 1 & $2(0.00,0.10)$ & 69 & 42 & $61(0.49,0.72)$ & 26 & 8 & $31(0.17,0.50)$ \\
\hline
\end{tabular}

+ Please note, $\mathrm{N}$ may vary from question to question. $* * * \mathrm{p}<.001$ 


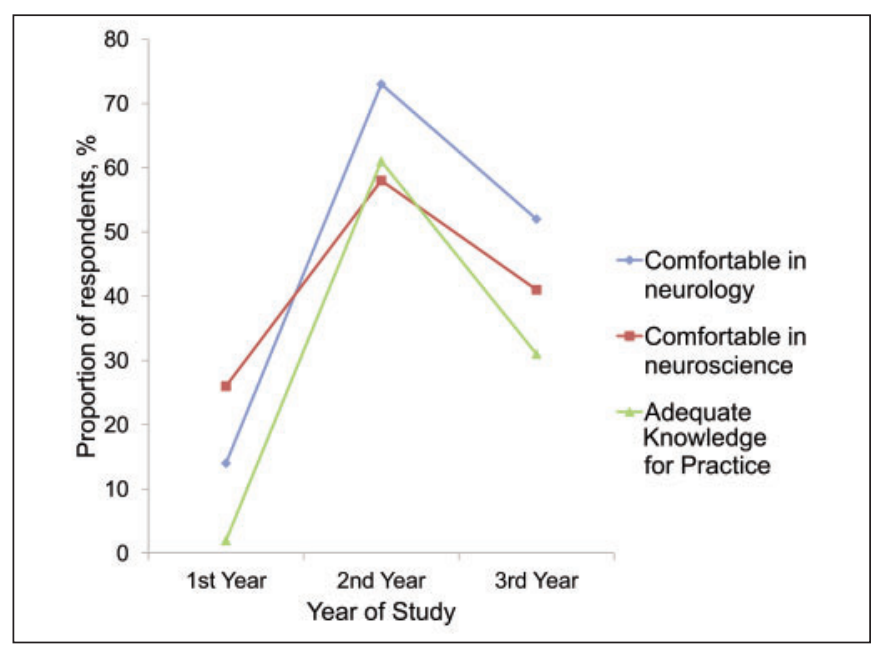

Figure 2: A sample of undergraduate medical students' perceptions of their training in neurology by year of study.

patients, and that a one-week rotation in clinical neurology would make them less neurophobic.

The development of neurophobia and the factors that contribute to its genesis.

Students identified a number of common themes that directly impacted their perceptions of neurology and sense of neurophobia. These neurophobia risk factors can be further subcategorized into modifiable and non-modifiable factors (Figure 3).

\section{Non-modifiable risk factors}

Non-modifiable risk factors include "Past Exposures to Neurology" and "Preconceptions" about the subspecialty. Students reported that whether educational, clinical, or personal, past exposures to neurology impacted their comfort level with the study of neurology (Table 4). Students also seemed to have formed opinions about neurology prior to entering medical school in general and the neurology block in particular. Common "Preconceptions" included perceptions related to the complexity of the field, the often perpetuated notion amongst students that the neurology block is the most difficult of the undergraduate blocks, and the belief that neurologists are amongst the unhappiest physicians outside of work.

\section{Modifiable risk factors}

Identified modifiable neurophobia risk factors included "Barriers to Learning" which comprised the complexity of terminology and perhaps more importantly the lack of return demonstrations across their undergraduate medical education; indeed, being exposed to neurology for a brief period of time in their second year without third or fourth year exposures to revisit the material, was seen as a barrier to their consolidation of the subject matter. Moreover, the timing of delivery of content, as well as the lack of clinical application when basic neuroscience concepts are taught were identified as barriers. Interestingly, students also noted the lack of standardized patients with clear neurological pathology during their simulation sessions as a barrier to learning.

In the third-year cohort, students commented on an alarming phenomenon summarized in the "Changes in Perspective" risk category; they shun away from the study of neurology in their senior clerkship years citing its "low yield value". Students were

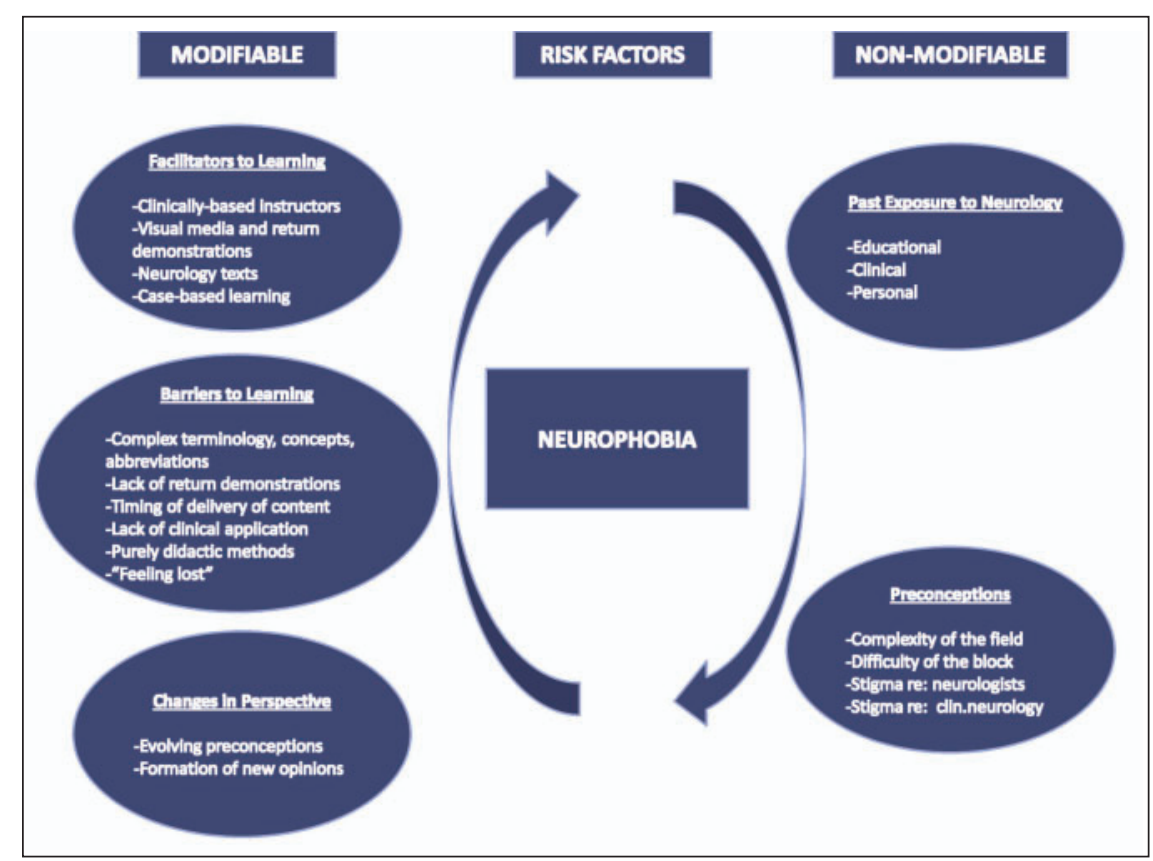

Figure 3: Risk factors for neurophobia emerging from focus group data. 
Table 4: Representative sample statements of major themes emerging from focus group data

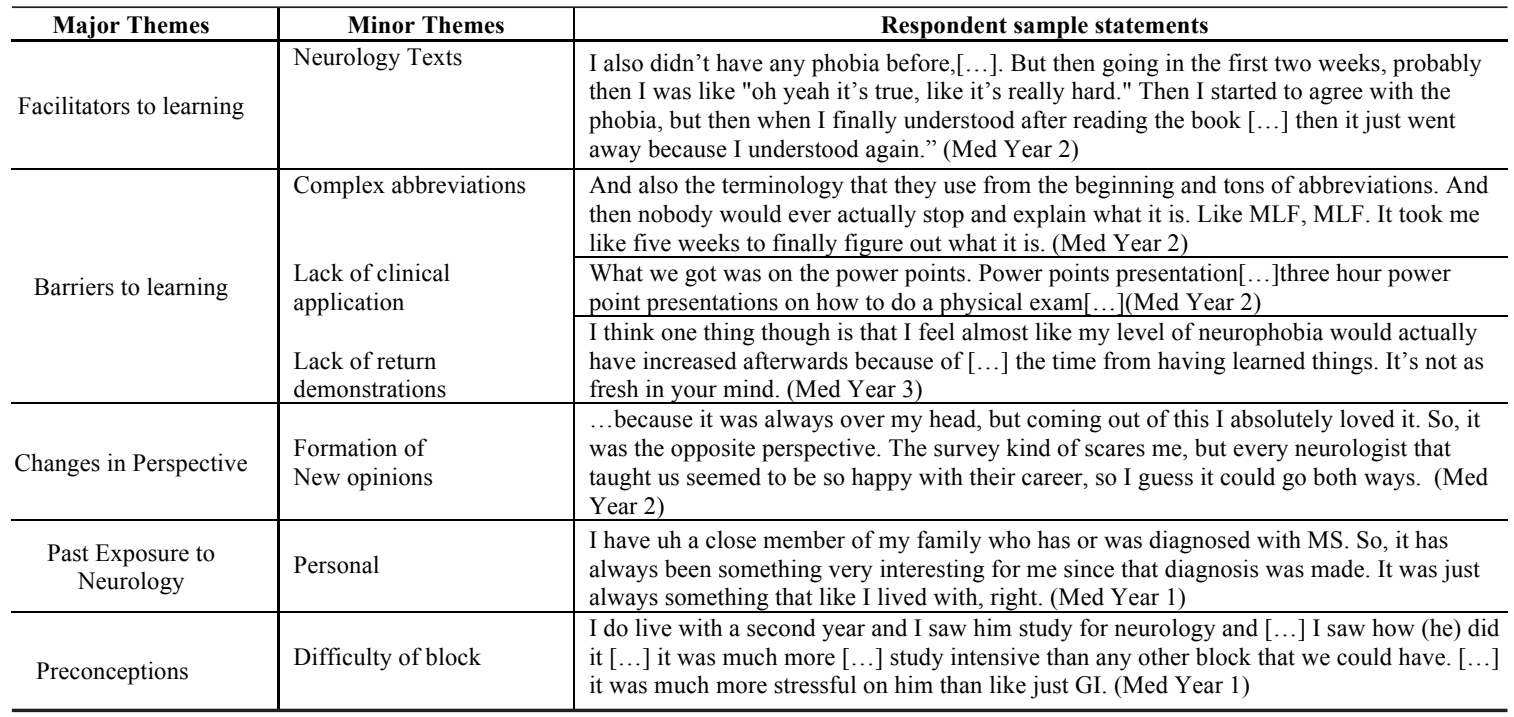

inclined to abandon the study of neurology as a subject of learning when it failed to align with their future scope of practice or residency aspirations.

\section{Discussion}

The first major finding of this study was that neurophobia in particular was present in all three undergraduate medical years and well established in first year medical students, despite showing no significant differences across the years of study. However, students' level of comfort with clinical neurology varied and was highest immediately upon completion of the institution's six week mandated neurology training block, as evidenced by the second-year respondents, of whom the majority thought they had adequate knowledge of clinical neurology for their future practice. However, by third year this comfort level appeared to "wear off" with more than half acknowledging their inadequate knowledge of clinical neurology for their practice. This finding suggests that there is a need for a more sustained reinforcement of neurological concepts across the entirety of undergraduate medical education. Though exposure to the neurology teaching block seemed to help students' comfort levels with the subject matter, it also heightened students' perception of neurology difficulty with two thirds of second- and third-year respondents acknowledging neurology's difficulty compared to a similar percentage of first-year respondents not appreciating whether this was, in fact, the case.

Prior studies have linked neurophobia genesis to medical school theorizing perhaps that exposure to the neurology curriculum affects trainees' perceptions of the difficulty of the discipline of neurology ${ }^{18}$. Our study design helps shed more light on the possible timing of precisely when this occurs in medical school. Taken together, our data would suggest that some neurophobia seems to predate medical school; students enter medical school with their own preconceptions and past exposures to the neurological sciences, all of which elicit neurophobia in as early as their first year. Their exposure to the neurology teaching block may transiently decrease their neurophobia by strengthening their comfort levels with the material, but this acquired comfort tends to decrease again during clerkship years.

The second major finding of this study was determining which factors contribute to the genesis of neurophobia during medical training. Among the identified non-modifiable risk factors, one particularly interesting finding appeared to be students' perception of neurologists being unhappy physicians. Some students admitted that this preconception came from a recent MedScape survey looking at physician satisfaction based on career choice ${ }^{19}$. This survey sampled some 30,000 U.S. physicians across 25 specialties and concluded that neurologists along with internists and gastroenterologists were the least happy amongst those surveyed. Neurologists were generalized to be "in poor health", "obese" as well as "separated" among other qualifiers used to describe them; statements that had a negative effect on students' perceptions of neurologists. It remains encouraging, however, that students participating in this study did in fact experience often positive and meaningful Changes in Perspective after finishing their Neurology blocks, suggesting that perhaps not all components of their preconceptions are nonmodifiable.

The modifiable risk factors highlighted in the Barriers to Learning and Changes in Perspective themes are similar to the ones commonly cited in neurophobia literature and include, amongst others, the complexity of the subject material and the difficulty of the neurological examination ${ }^{6-9}$. These modifiable neurophobia substrates need to be intensely targeted during the pre-clinical undergraduate medical curriculum to prevent the resurgence of neurophobia in the clerkship years, as evidenced by the "wearing off " effect noted in our third-year cohort of students, perhaps more aptly entitled "neuramnesia". 
The dissemination of skills or knowledge through multiple sessions spaced throughout the length of a curriculum is known as 'distributed practice'. This practice, when applied to neurological teaching in medical school, has been shown to improve students' performance with aspects of their neurological knowledge such as the neurological examination. In one study, it demonstrated a sustained benefit 14 months after the last intervention ${ }^{20}$. This methodology forms the basis of the AAN Subcommittee on undergraduate neurology education's outline of objectives of the core requirements for the clinical neurology clerkship as they have advocated for its implementation at all levels of the undergraduate curriculum, from first-year neuroscience courses to fourth-year clinical electives. This would result in a sustained and constant exposure to the discipline of clinical neurology thereby potentially preventing the instillation of neurophobia ${ }^{21,22}$. Fittingly, in our study, across all surveyed years, students showed overwhelming support in implementing a one-week clinical rotation to cement principles learned in their six-week Neurology block.

This study helps shed more light on the factors that contribute to students' sense of neurophobia at different time points in their undergraduate careers. Its main limitation was that it was conducted in a single centre and relied on students' voluntary participation. In contrast to the U.S., our medical school, like most Canadian medical schools, does not mandate a neurology rotation as part of the core clerkship curriculum. These factors may limit the generalizability of our study. Furthermore the low response rates, seen especially in the third year group, may also increase bias. However, this study showed that a mixed-methods study design is desirable in approaching the subject of neurophobia as it provides a more in-depth exploration of students' perceptions surrounding their undergraduate neurology education. As the population demographic continues to change, institutions must show a greater degree of flexibility in allotting the neurological sciences greater weight in the medical curriculum to provide an effective front against the phenomenon of neurophobia.

\section{ACKNOWLEDGements}

The authors thank Dr. Niall Tubridy for his invaluable insight during the development of our Phase 1 questionnaire.

\section{STUdY Funding}

Supported by the Academy for Innovation in Medical Education of the Faculty of Medicine of the University of Ottawa.

\section{Author Contributions}

Dr. Tadeu Fantaneanu conceived the project, helped with study design, participated in writing the study protocol, and was the principal writer of the manuscript.

Katherine Moreau helped with study design, participated in writing the study protocol, oversaw data collection, analysis, and interpretation, and contributed to the writing and editing of the manuscript.

Kaylee Eady and Chantalle Clarkin helped with study design, collected, analyzed, and interpreted the data, and contributed to the writing and editing of the manuscript.
Drs. Christine De Meulemeester and Heather Maclean helped with study design, participated in the writing of the manuscript and reviewed all manuscript drafts.

Dr. Asif Doja helped with study conception and design, participated in writing the study protocol, oversaw all study activities, and contributed to the writing and editing of the manuscript.

\section{REFERENCES}

1. Dorsey ER, Constantinescu R, Thompson JP et al. Projected number of people with Parkinson disease in the most populous nations, 2005 through 2030. Neurology. 2007;68:384-6.

2. Hirtz D, Thurman DJ, Gwinn-Hardy K, Mohamed M, Chaudhuri AR, Zalutsky R. How common are the "common" neurologic disorders? Neurology. 2007;68:326-37.

3. Canadian Institute for Health Information [Internet]. The burden of neurological diseases, disorders and injuries in Canada. Ottawa: CIHI 2007 [cited 2011 Jul 2]. Available from: http://www.cpa.ca/cpasite/userfiles/Documents/Practice_Page/B urden_neuro_diseases_en.pdf.

4. Jozefowicz R. Neurophobia: the fear of neurology among medical students. Arch Neurol. 1994;51:328-9.

5. Poser CM. Undergraduate attitudes toward the specialty of neurology. Neurology. 1959;9:682-8.

6. Schon F, Hart P, Fernandez C. Is clinical neurology really so difficult? J Neurol Neurosurg Psychiatry. 2002;72:557-9.

7. Flanagan E, Walsh C, Tubridy N. 'Neurophobia'--Attitudes of medical students and doctors in Ireland to neurological teaching. Eur J Neurol. 2007;14:1109-12.

8. Youssef F. Neurophobia and its implications: evidence from a Caribbean medical school. BMC Med Educ. 2009 Jul 1;9:39.

9. Zinchuk AV, Flanagan EP, Tubridy NJ, Miller WA, McCullough LD. Attitudes of US medical trainees towards neurology education: "neurophobia"- a global issue. BMC Med Educ. 2010 Jun 23;10:49.

10. Matthias AT, Nagasingha P, Ranasinghe P, Gunatilake SB. Neurophobia among medical students and non-specialist doctors in Sri Lanka. BMC Med Educ. 2013 Dec 9;13(1):164.

11. Gupta NB, Khadilkar SV, Bangar SS, Patil TR, Chaudhari CR. Neurology as career option among postgraduate medical students. Ann Indian Acad Neurol. 2013 Oct;16(4):478-82.

12. Creswell JW. Research Design: qualitative, quantitative, and mixed methods approaches. 3rd ed. Los Angeles, CA: Sage Publications, Inc; 2009.

13. Patton MQ. Qualitative research and evaluation methods. Thousand Oaks, CA: Sage Publications, Inc; 2002.

14. Colton D, Covert RW. Designing and constructing instruments for social research and evaluation. 1st ed. San Francisco, CA: Jossey-Bass; 2007.

15. Dillman D. Mail and internet surveys: the tailored design method. New York, NY: John Wiley \& Sons; 2000.

16. Hsieh H, Shannon SE. Three approaches to qualitative content analysis. Qual Health Res. 2005;15:1277-88.

17. Tesch R. Qualitative research: analysis types and software tools. Bristol, PA: Falmer; 1990.

18. Ridsdale L, Massey R, Clark L. Preventing neurophobia in medical students, and so future doctors. Pract Neurol. 2007;7:116-23.

19. Medscape.com [Internet]. New York: WebMD LLC; C1994-2014 [cited 2012 May 1]. Available from: http://www.medscape.com/ features/slideshow/lifestyle/2012/public.

20. Moore F, Chalk C. Improving the neurological exam skills of medical students. Can J Neurol Sci. 2012;39:83-6.

21. Gelb DJ, Gunderson CH, Henry KA, Jozefowicz RF. The neurology clerkship core curriculum. Neurology. 2002;58:84952.

22. Charles PD, Scherokman B, Jozefowicz RF. How much neurology should a medical student learn? A position statement of the AAN undergraduate education subcommittee. Acad Med. 1999;74: 23-6. 


\section{Supplemental e-1: Phase 1 Questionnaire}

Understanding the genesis of neurophobia: A mixed-methods study of trainees' perceptions of neurology education (Phase 1)

We would like to invite you to complete this survey so that we can better understand your perceptions of neuroscience and neurology.

We are interested in your honest opinions, whether they are positive or negative.

Please select your answer choices.

1. What is your current year of study?

\begin{tabular}{|c|c|c|c|}
\hline First Year & Second Year & Third Year & Other (specify) \\
\hline
\end{tabular}

\begin{tabular}{|c|c|c|c|c|c|}
\hline $\begin{array}{l}\text { 2. Please indicate the extent to which you agree or disagree with the } \\
\text { following statements. NOTE: These questions refer to your medical } \\
\text { school training to date and not to previous undergraduate training. }\end{array}$ & $\begin{array}{l}\text { Strongly } \\
\text { Disagree }\end{array}$ & Disagree & Agree & $\begin{array}{l}\text { Strongly } \\
\text { Agree }\end{array}$ & Don't Know \\
\hline \multicolumn{6}{|l|}{ I think neurology is important to the study of medicine in general. } \\
\hline \multicolumn{6}{|l|}{ I think neuroscience is important to the study of medicine in general. } \\
\hline \multicolumn{6}{|l|}{$\begin{array}{l}\text { I think neurology is important for general practitioners (i.e., family } \\
\text { physicians, general internists, general pediatricians). }\end{array}$} \\
\hline \multicolumn{6}{|l|}{ I am happy with the amount of education I have received in neurology. } \\
\hline \multicolumn{6}{|l|}{$\begin{array}{l}\text { I am happy with the amount of education I have received in } \\
\text { neuroscience. }\end{array}$} \\
\hline \multicolumn{6}{|l|}{ I am happy with the type of education I have received in neurology. } \\
\hline \multicolumn{6}{|l|}{ I am happy with the type of education I have received in neuroscience. } \\
\hline \multicolumn{6}{|l|}{ I am comfortable with the subject of neurology. } \\
\hline \multicolumn{6}{|l|}{ I am comfortable with neuroscience. } \\
\hline \multicolumn{6}{|l|}{ I have adequate knowledge of neurology. } \\
\hline \multicolumn{6}{|l|}{ I have adequate knowledge of neuroscience. } \\
\hline \multicolumn{6}{|l|}{ I think neuroanatomy is difficult. } \\
\hline \multicolumn{6}{|l|}{ I think neurology is difficult. } \\
\hline \multicolumn{6}{|l|}{ I think neurology is one of the most difficult disciplines in medicine. } \\
\hline \multicolumn{6}{|l|}{ I have had limited exposure to neurological patients. } \\
\hline \multicolumn{6}{|l|}{ I would like to have more exposure to neurological patients. } \\
\hline \multicolumn{6}{|l|}{ I am afraid of neurology. } \\
\hline I am afraid of neuroscience. & & & & & \\
\hline
\end{tabular}

3. If eligible, would you be interested in participating in a follow up FOCUS GROUP for this study (Note: all focus groups will be conducted in English)?

Yes, please email additional information to me at: (please insert your email address)
Maybe, please email additional information to me at: (please insert your email address)
No, not at this time. 


\section{Supplemental e-2: Phase 2 Focus Group Guide}

\section{Understanding the Genesis of Neurophobia: A Mixed-Methods Study of Trainees' Perceptions of Neurology Education}

Thank you for taking the time to talk to us about medical students' potential apprehension towards the neurological sciences during their training years. Since the burden of neurological illness will rise in the next decades, we are interested in exploring the topic of "neurophobia". This study examines the extent neurophobia exists amongst medical students and explores factors that contribute to its development.

The information that you share in the focus group will be kept confidential. Because the focus group will be conducted in person with other individuals, your anonymity cannot be protected. However, only us and the other focus group participants will know your identity and responses. Everyone will be asked to keep one another's identity and responses confidential. Any information that may reveal your identity (e.g., name) will be erased from the audio-recording and transcript so that you cannot be identified.

Before we begin, I would like to remind you that there are no correct answers. Your participation is voluntary. You do not have to answer any questions that make you feel uncomfortable.

1. What is your current level of interest in clinical Neurology?

2. How would you describe your current comfort level in clinical Neurology?

3. How much teaching and training have you had in the Neurosciences and Neurology? Do you think you received enough teaching and training? Describe.

4. To date, what has your personal experience been with Clinical Neurology?

5. What does the term neurophobia mean to you?

Neurology has traditionally been perceived as one of the more difficult clinical sub-specialties and as such, the term neurophobia was coined to describe the fear of neural sciences and neurology among medical students and doctors.

1. What are your thoughts on neurophobia?

2. Describe whether you think neurophobia exists among medical students.

3. Why do you think some medical students are neurophobic?

4. Describe the degree to which you are neurophobic.

5. Why are you neurophobic?

6. What part of clinical Neurology are your most afraid of?

7. When do you think neurophobia develops?

8. How do you think neurophobia develops?

Our survey results on the extent to which neurophobia exist among medical students revealed, that most students would like more exposure to neurological patients.

1. In your opinions, what impact would this increased exposure have on your comfort level or that of your peers in clinical Neurology?

2. In your opinions, what else can we do to minimize your neurophobia or neurophobia among medical students?

3. Is there anything else you would like to discuss that we did not discuss today?

At this time, I would like to thank you for your participation. Your contribution to this study has been beneficial and insightful. If you have any further comments or questions please contact me. My contact information is included on your copy of the consent form. 